\title{
Principal Component Analysis on the Twitter Data in the Restaurant Industry
}

\author{
Koumei Suzuki ${ }^{1}$, Yuki Higuchi ${ }^{2}$, Kazuhiro Takeyasu ${ }^{3}$ \\ ${ }^{1}$ Graduate School of Humanities and Social Sciences, Shizuoka University, Shizuoka ,Japan \\ ${ }^{2}$ Faculty of Business Administration, Setsunan University, Osaka, Japan \\ ${ }^{3}$ College of Business Administration, Tokoha University, Shizuoka, Japan \\ Correspondence: Koumei Suzuki, Only Sky Co. 4-25-5 Yoshiwara, Fuji city Shizuoka, Japan.
}

Received: November 21, 2018

Accepted: December 18, 2018 Online Published: December 24, 2018

doi:10.5539/ibr.v12n1p88

URL: https://doi.org/10.5539/ibr.v12n1p88

\begin{abstract}
Social Networking Service (SNS) is prevailing rapidly in Japan in recent years. Facebook, mixi and Twitter are the popular one. These are utilized in various field of life together with the convenient tool such as smart-phone. In this paper, principal component analysis and cluster analysis are executed in order to clarify the relationship among the corporate performance and the SNS utilization condition. We focus on restaurant industry and convenience store industry, where marketing competition which utilizes SNS to consumers is fierce. Marketing application would then be extracted. Reviewing past researches, there are some related papers, but they do not handle these analysis techniques. Moreover there have been few researches made on our theme stated above. Some interesting results were obtained.
\end{abstract}

Keywords: SNS, twitter, twitter followers, principal component analysis, cluster analysis

\section{Introduction}

Social Networking Service (SNS) is prevailing rapidly in Japan in recent years. Facebook, mixi and twitter are the popular one. In particular, the number of users is increasing year by year and it has reached 328 million users at the point of September 2017.These are utilized in various field of life together with the convenient tool such as smart-phone. Twitter is well used in the marketing activities of each company. They carry out campaign through SNS, which become very popular in Japan. It is reported that many companies have improved corporate performance by utilizing SNS. In this paper, principal component analysis and cluster analysis are executed in order to clarify the relationship among the corporate performance and the SNS utilization condition. We focus on restaurant industry and convenience store industry, where marketing competition which utilizes SNS to consumers is fierce. Marketing application would then be extracted. Reviewing past researches, there are some related papers, but they do not handle these analysis techniques. Moreover there have been few researches made on our theme stated above. Some interesting results were obtained.

Reviewing past researches, Sako et al. (2013) devised the system to identify the user's sex by extracting characteristics from the tweet big data through using Support Vector Machine. Kadowaki et al. (2014) proposed the method to inquire recipe which fit to the user by the analysis of twitter text. Tamai et al. (2016) estimated the degree of depression from the tweet data.

There are many related papers concerning twitter but there are few papers which analyze the correlation between twitter related data and corporate performance by using principal component analysis and/or cluster analysis.

The rest of the paper is organized as follows. Principal component analysis is executed in section 2. Cluster analysis is carried out in section 3, which is followed by the Remarks of section 4.

\section{Principal Component Analysis}

The analysis data for restaurant industry and convenience industry is attached in Appendix. Most of the big and famous companies are covered. Principal component analysis is executed on these data. Analysis results are as follows. Eigen value and cumulative hitting ratio are exhibited in Table 1. 
Table 1. Eigen value and Cumulative hitting ratio

\begin{tabular}{ccc}
\hline Component & Eigen value & Cumulative hitting ratio \% \\
\hline 1 & 7.542 & 44.364 \\
2 & 2.600 & 59.657 \\
3 & 2.051 & 71.724 \\
4 & 1.674 & 81.569 \\
5 & .930 & 87.040 \\
6 & .835 & 91.952 \\
7 & .597 & 95.462 \\
8 & .321 & 97.352 \\
9 & .271 & 98.944 \\
10 & .084 & 99.438 \\
11 & .057 & 99.771 \\
12 & .018 & 99.877 \\
13 & .010 & 99.937 \\
14 & .009 & 99.989 \\
15 & .001 & 99.996 \\
16 & .001 & 100.000 \\
17 & .000004325 & 100.000 \\
\hline
\end{tabular}

Cumulative hitting ratio of the 1st principal component is $44.364 \%$ and cumulative hitting ratio up to the 2nd principal component is $59.657 \%$, 3rd principal component is $71.724 \%$ th is $81.569 \%$. i.e., nearly $60 \%$ of the data is explained by up to the 2nd principal component and over $80 \%$ of the data is explained by up to the 4th principal component.

Next, factor loading matrix is exhibited in Table 2. In this Table, up to 4th principal component is exhibited.

Table 2. Factor Loading Matrix

\begin{tabular}{lcccc}
\hline & Factor 1 & Factor 2 & Factor 3 & Factor 4 \\
\hline Total assets & .916 & .167 & -.312 & -.001 \\
Net Income & .890 & .199 & -.326 & .058 \\
Operating Income & .875 & .183 & -.364 & .027 \\
Ordinary income & .873 & .183 & -.375 & .024 \\
Number of stores & .828 & .075 & -.146 & -.078 \\
Number of tweets & .802 & .058 & .358 & -.402 \\
twitter followers & .791 & .537 & .035 & -.017 \\
replies & .723 & -.266 & .336 & .409 \\
amount of sales & .708 & .248 & .424 & -.106 \\
user mentions & .640 & -.309 & .346 & .375 \\
Number of twitter follow & .628 & .017 & .565 & -.443 \\
retweets & -.306 & .756 & -.088 & .085 \\
tweets retweeted & -.495 & .692 & .062 & -.283 \\
tweets favorited & -.496 & .672 & .060 & -.223 \\
links & -.009 & .018 & .696 & -.223 \\
hashtags & -.089 & .355 & .337 & .690 \\
Number of likes & -.075 & .558 & .282 & .567 \\
\hline Next, plot chart in
\end{tabular}

Next, plot chart is exhibited in Figure 1 where $\mathrm{X}$ axis is the 1st principal component and $\mathrm{Y}$ axis is the 2nd principal component. 


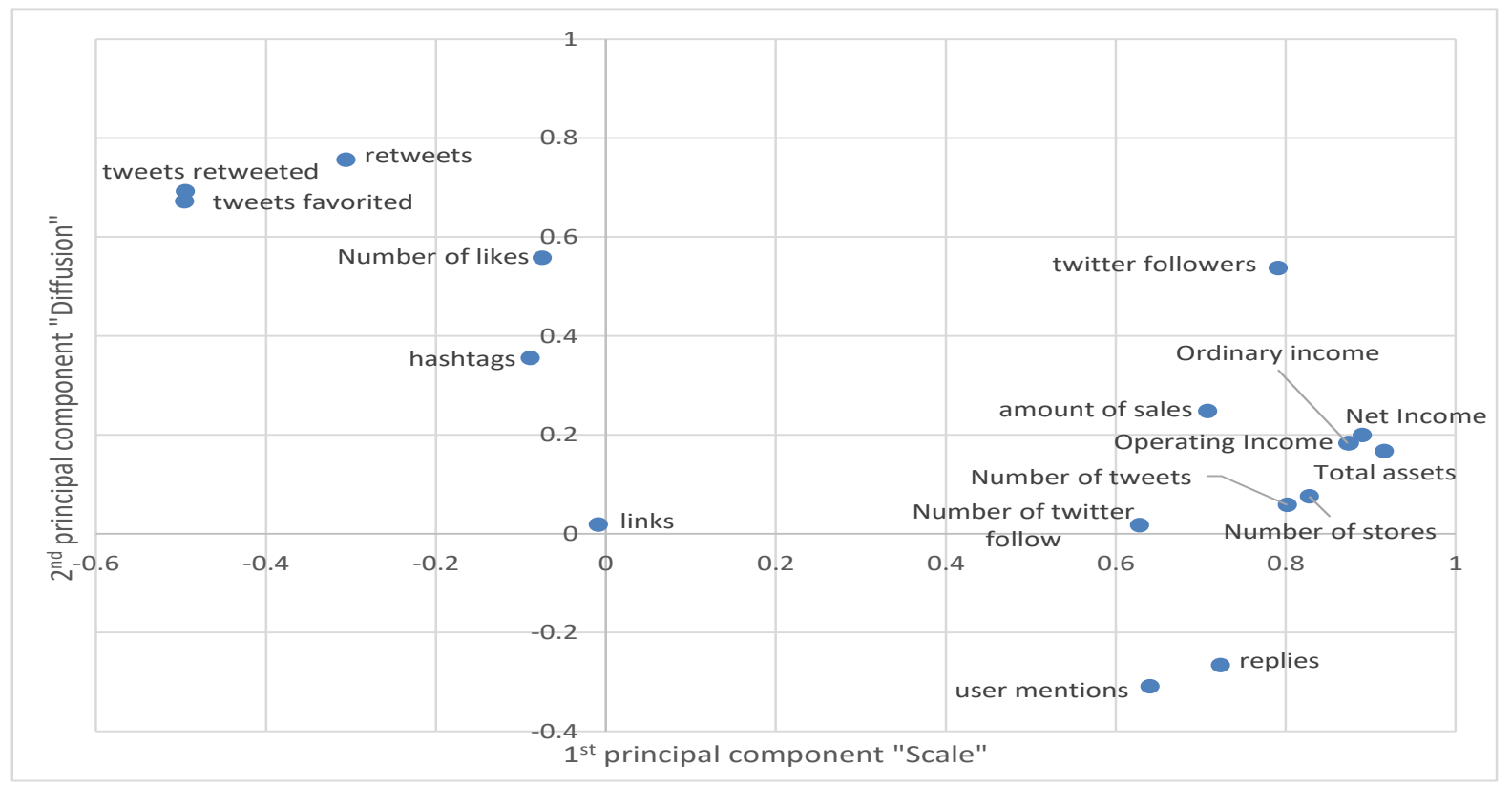

Figure 1. Plot chart of 1st principal component and 2nd principal component

The 1st principal component shows scale, corporate performance, number of tweets, number of followers etc., which means "Scale". The 2nd principal component has a large value at retweets, tweets retweeted, tweets favorited, which implies "Diffusion".

Next, plot chart is exhibited in Figure 2 for the 3rd principal component ( $\mathrm{X}$ axis) and the 4th principal component (Y axis).

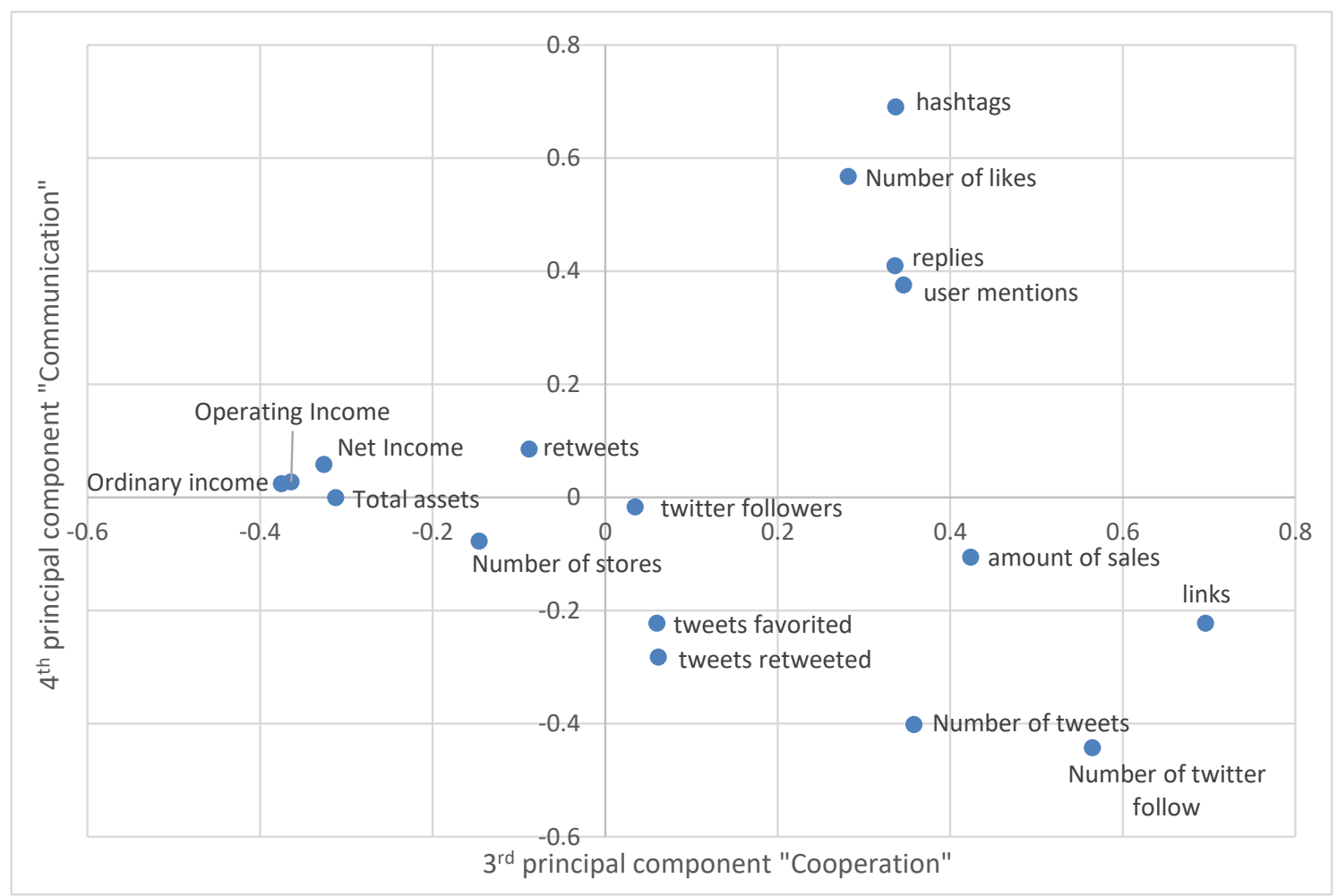

Figure 2. Plot chart of 3rd principal component and 4th principal component 
Y The 3rd principal component has a large value at links, number of followers etc., which means "Cooperation". The 4th principal component shows hashtags, number of likes, replies etc., which implies "Communication".

Now, the score for each company is exhibited in Table 3 where up to 4th principal component are shown.

Table 3. Score for each company

\begin{tabular}{|c|c|c|c|c|}
\hline Company Name & Factor 1 & Factor 2 & Factor 3 & Factor 4 \\
\hline Lawson & 2.42283 & 0.14188 & 2.37471 & -1.97311 \\
\hline Seven \& i Holdings & 2.80948 & 0.82845 & -2.48136 & 0.54066 \\
\hline FamilyMart & 1.07412 & -0.63105 & -0.27529 & -0.12329 \\
\hline KFC Holdings Japan & 0.08515 & -0.47491 & 1.64471 & 2.21423 \\
\hline ANRAKUTEI & -0.48214 & -0.53992 & -0.34107 & -0.26968 \\
\hline Plenus (Hotto Motto) & -0.36807 & 0.31295 & 0.17732 & -0.21455 \\
\hline B-R 31 ICE CREAM & -0.06776 & -1.35694 & 0.71867 & 0.37918 \\
\hline MINISTOP & -0.4068 & 0.82209 & 0.65113 & -0.56251 \\
\hline McDonald's Holdings Company (Japan) & -0.45266 & 3.11114 & 0.31551 & 1.00773 \\
\hline SKYLARK (GUSTO) & 0.56741 & -0.49616 & 0.55266 & 2.20142 \\
\hline KURA Corporation & -0.70145 & 0.76172 & 0.2195 & -0.87386 \\
\hline KAPPA CREATE & -0.58062 & -0.65942 & 0.14445 & -0.9163 \\
\hline MOS FOOD SERVICES & -0.69925 & 0.83189 & -0.25741 & -1.04256 \\
\hline Torikizoku & -0.14886 & -1.18067 & -0.14184 & 0.33088 \\
\hline CHIKARANOMOTO GLOBAL HOLDINGS (IPPUDO) & -0.68238 & 0.65007 & 0.15277 & 0.52569 \\
\hline RINGER HUT & -0.55311 & -0.17269 & -0.17231 & -0.18492 \\
\hline KOURAKUEN HOLDINGS & -0.62458 & -0.20648 & -0.70228 & -0.30892 \\
\hline HOTLAND (Tsukiji Gindako) & -0.55063 & -0.21304 & -0.84945 & -0.02372 \\
\hline AKINDO SUSHIRO & -0.30514 & -0.64715 & -0.7976 & -0.36096 \\
\hline TORIDOLL (MARUKAME UDON) & -0.33556 & -0.88177 & -0.93282 & -0.34543 \\
\hline
\end{tabular}

Next, plot chart is exhibited in Figure 3 (The 1st principal component for $\mathrm{X}$ axis and the 2nd principal component for Y axis).

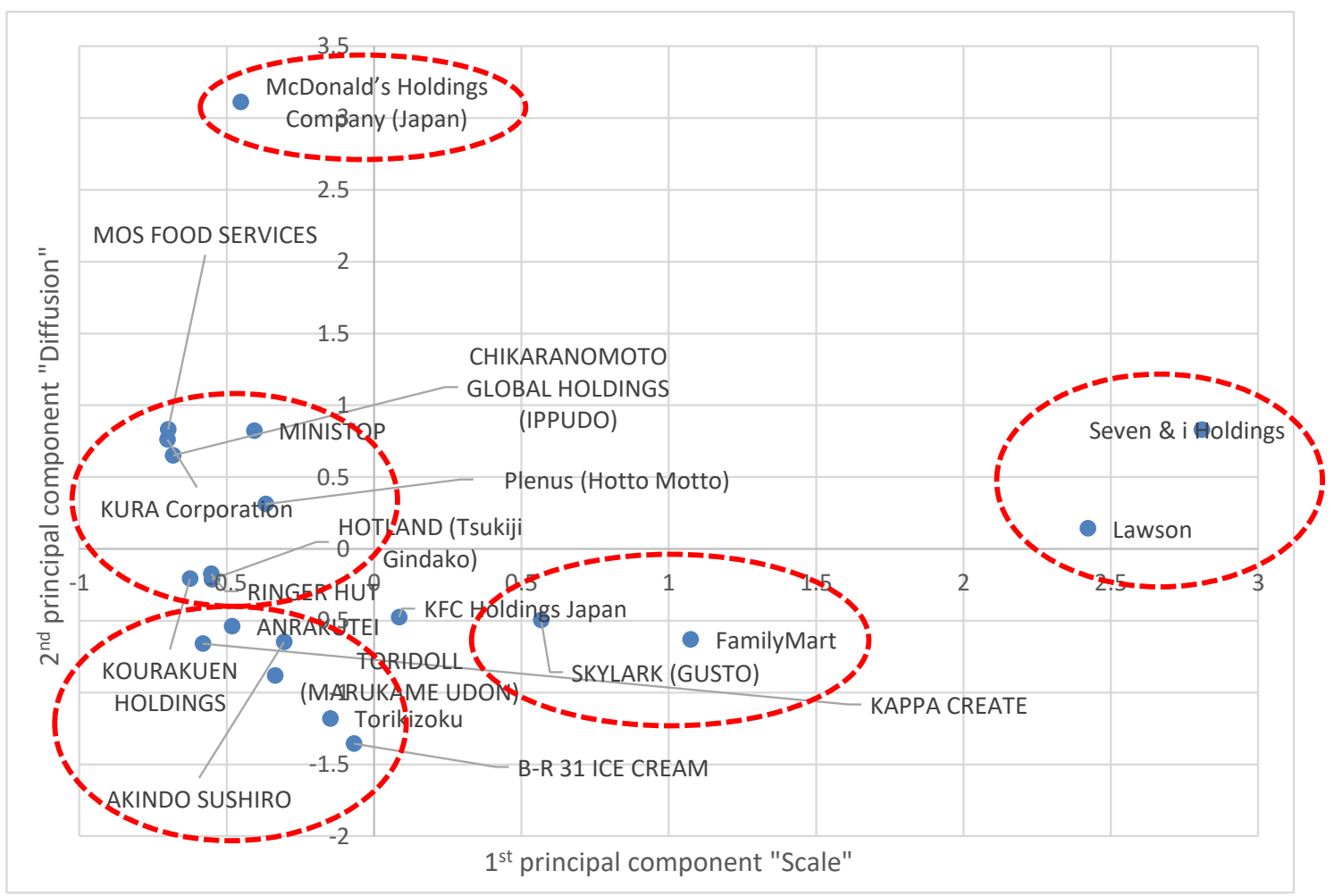

Figure 3. Plot chart (The 1st principal component for $\mathrm{X}$ axis and the 2nd principal component for $\mathrm{Y}$ axis)

We can observe the following 5 big clusters.

Right: Seven \& i Holdings, Lawson

This is a high corporate performance, high frequency SNS utilization group.

Left Upper: McDonald's Holdings Company (Japan) 
This is a single group. It is strong for retweets group. It makes many campaign and has good communication with consumers.

\section{Lower Right: KFC Holdings Japan, SKYLARK (GUSTO), FamilyMart}

This cluster has the characteristics that corporate performance and scale are rather big and retweets group are slightly low.

\section{Left: MOS FOOD SERVICES, KURA Corporation, Plenus (Hotto Motto), MINISTOP}

MOS FOOD SERVICES carries out the campaign, where the rival is McDonald. But it does not make so much hit as McDonald in the number of retweets.

Lower Left: ANRAKUTEI, Torikizoku, KAPPA CREATE, RINGER HUT, B-R 31 ICE CREAM, KOURAKUEN HOLDINGS, Torikizoku

Scale is rather small and the number of tweets is rather few. They do not make so much effort to SNS or it does not make so much hit.

Next, plot chart is exhibited in Figure 4 where the 3rd principal component is located at $\mathrm{X}$ axis and the 4th principal component is placed at $\mathrm{Y}$ axis.

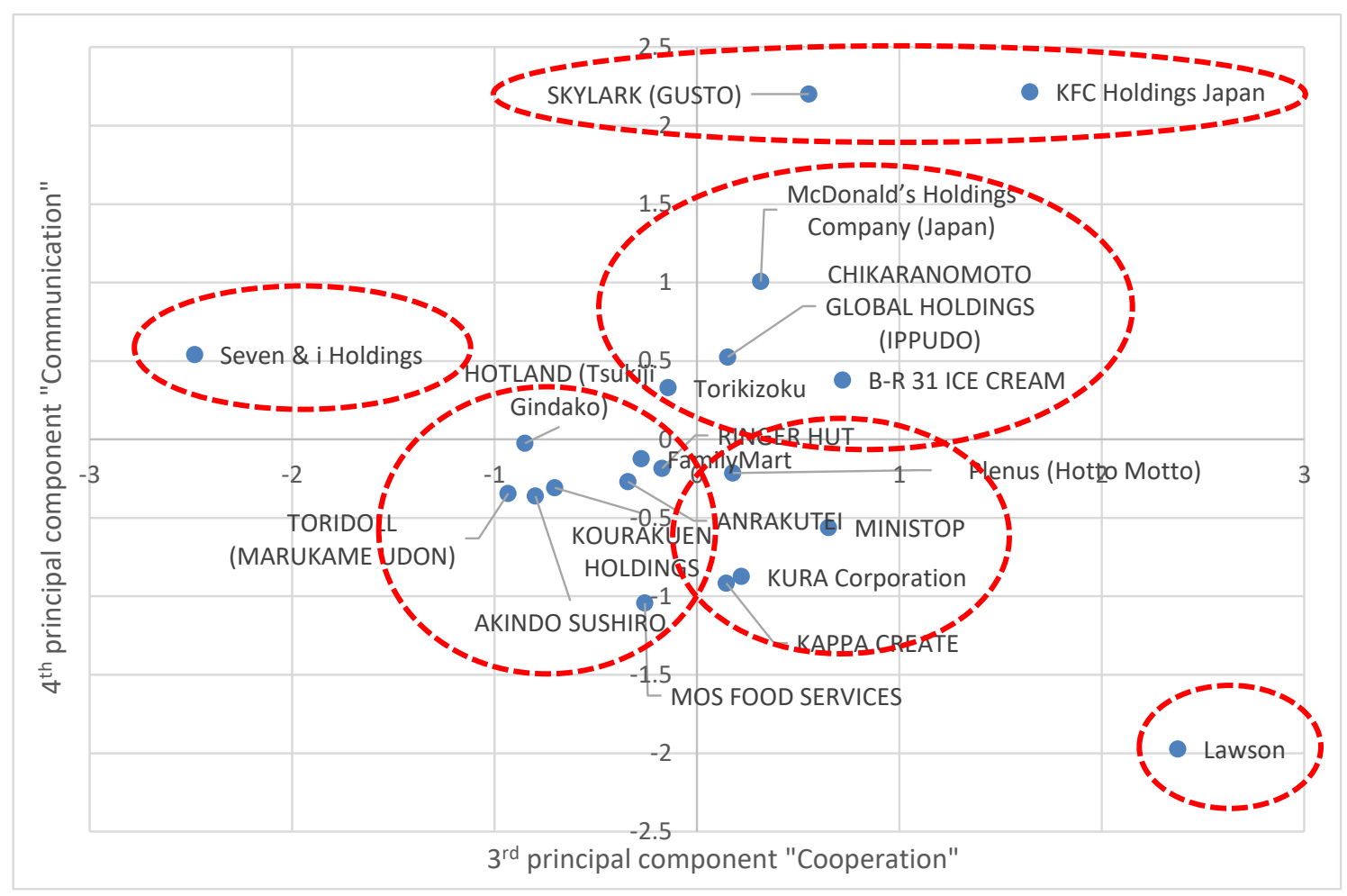

Figure 4. Plot chart (the 3rd principal component is located at $\mathrm{X}$ axis and the 4th principal component is placed at $\mathrm{Y}$ axis)

We can observe the following 6 clusters.

Upper Right: KFC Holdings Japan, SKYLARK (GUSTO)

Although the number of retweets is slightly small, there are many reply from the company. Therefore it is regarded as a high communication group.

Lower Right: Lawson

It has many followers and links but communication level is low.

Center Upper Right: McDonald's Holdings Company (Japan), B-R 31 ICE CREAM, Torikizoku

Communication and the number of followers are rather high. It can be said that they make effort to a certain degree. 


\section{Center Right Lower: MINISTOP, KAPPA CREATE, KURA Corporation}

They have certain number of followers but communication level is low.

\section{Center Left Lower: KOURAKUEN HOLDINGS, AKINDO SUSHIRO, MOS FOOD SERVICES,} ANRAKUTEI

It is in the low level communication and the number of followers is in the low level. It can be said that it is a low active group in SNS.

Thus we could obtain fruitful results by utilizing principal component analysis.

\section{Cluster Analysis}

Cluster analysis is executed in order to confirm the relationship/closeness among companies. The data used are the same with those of principal component analysis. First of all, cluster cohesion process is exhibited in Table 4.

Table 1. Cluster Cohesion Process

\begin{tabular}{|c|c|c|c|c|c|c|}
\hline \multirow[b]{2}{*}{ Steps } & \multicolumn{2}{|c|}{ Combined Cluster } & \multirow[b]{2}{*}{ Coefficient } & \multicolumn{2}{|c|}{ First stage of cluster } & \multirow[b]{2}{*}{ Next step } \\
\hline & Cluster 1 & Cluster 2 & & Cluster 1 & Cluster 2 & \\
\hline 1 & 21 & 24 & .235 & 0 & 0 & 9 \\
\hline 2 & 18 & 19 & 1.326 & 0 & 0 & 7 \\
\hline 3 & 8 & 10 & 2.625 & 0 & 0 & 6 \\
\hline 4 & 13 & 15 & 4.287 & 0 & 0 & 6 \\
\hline 5 & 5 & 16 & 6.672 & 0 & 0 & 10 \\
\hline 6 & 8 & 13 & 10.094 & 3 & 4 & 14 \\
\hline 7 & 17 & 18 & 13.579 & 0 & 2 & 8 \\
\hline 8 & 17 & 20 & 18.941 & 7 & 0 & 11 \\
\hline 9 & 14 & 21 & 24.791 & 0 & 1 & 11 \\
\hline 10 & 5 & 9 & 31.222 & 5 & 0 & 12 \\
\hline 11 & 14 & 17 & 39.106 & 9 & 8 & 12 \\
\hline 12 & 5 & 14 & 52.321 & 10 & 11 & 14 \\
\hline 13 & 4 & 12 & 67.046 & 0 & 0 & 15 \\
\hline 14 & 5 & 8 & 87.763 & 12 & 6 & 17 \\
\hline 15 & 3 & 4 & 108.636 & 0 & 13 & 18 \\
\hline 16 & 1 & 2 & 144.735 & 0 & 0 & 19 \\
\hline 17 & 5 & 11 & 181.154 & 14 & 0 & 18 \\
\hline 18 & 3 & 5 & 223.698 & 15 & 17 & 19 \\
\hline 19 & 1 & 3 & 360.349 & 16 & 18 & 0 \\
\hline
\end{tabular}

Distance is calculated by using Euclidean square distance. Dendrogram by Ward method is exhibited in Figure 5.

AKINDO SUSHIRO
TORIDOLL (MARUKAME UDON)
KAPPA CREATE
RINGER HUT
KOURAKUEN HOLDINGS
CHIKARANOMOTO GLOBAL HOLDINGS (IPPUDO)
HOTLAND (Tsukiji Gindako)
ANRAKUTEI
Torikizoku
B-R 31 ICE CREAM
PlenUs (Hotto Motto)
MINISTOP
KURA Corporation
MOS FOOD SERVICES
MCDonald's Holdings Company (Japan)
KFC Holdings Japan
SKYLARK (GUSTO)
FamilyMart
Lawson
Seven \& i Holdings

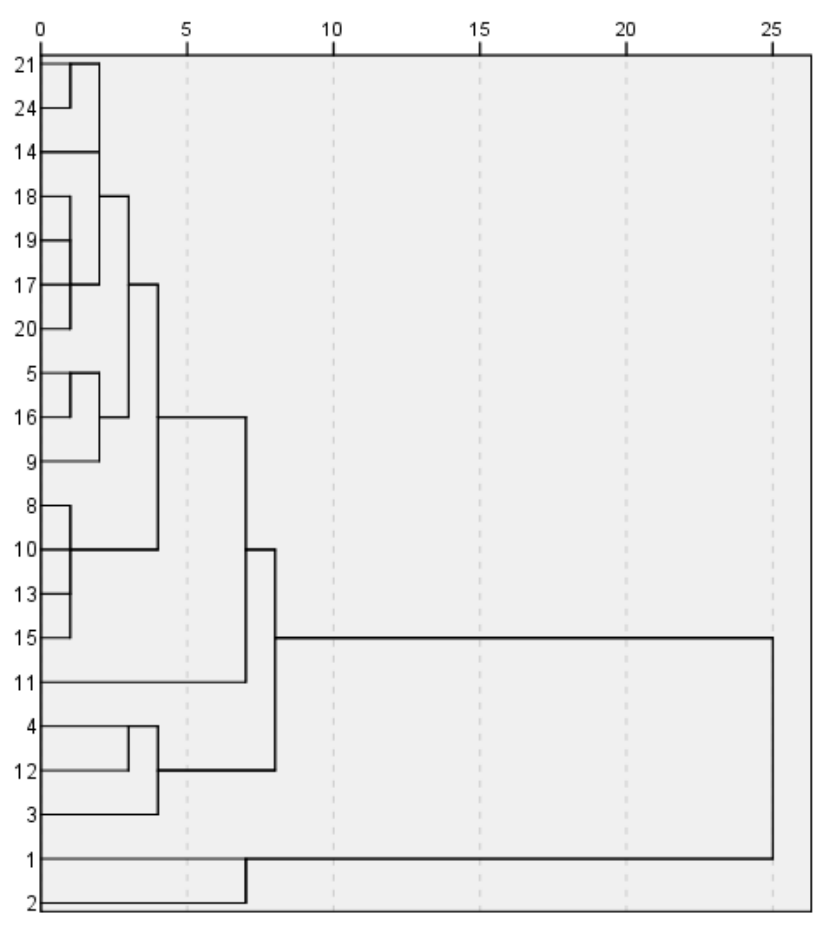

Figure 5. Dendrogram by Ward method 
Watching carefully in detail, we could find astonishing results. In the principal component analysis for the 1st principal component and the 2 nd principal component, we could observe 5 big clusters. Cluster analysis wholly coincided with these results. 3.

The group of AKINDO SUSHIRO B-R 31 ICE CREAM is the same with those of Lower Left in Figure

The group of Plenus (Hotto Motto) MOS FOOD SERVICES is the same with those of Left Center in Figure 3.

McDonald's Holdings Company (Japan) corresponds to Left Upper in Figure 3.

KFC Holdings Japan FamilyMart group is the same with those of Lower Right in Figure 3.

Lawson, Seven \& i Holdings is located right in Figure 3.

Examining it more in detail, we could find that the classification by Cluster analysis corresponds to the positive part of 1st principal component, negative part of 1st principal component, positive part of 2nd principal component and negative part of 2 nd principal component. If we indicate large positive part of 1st principal component as ++ , and small one as + , then the expression by the combination of (1st principal component, 2nd principal component) become as follows.

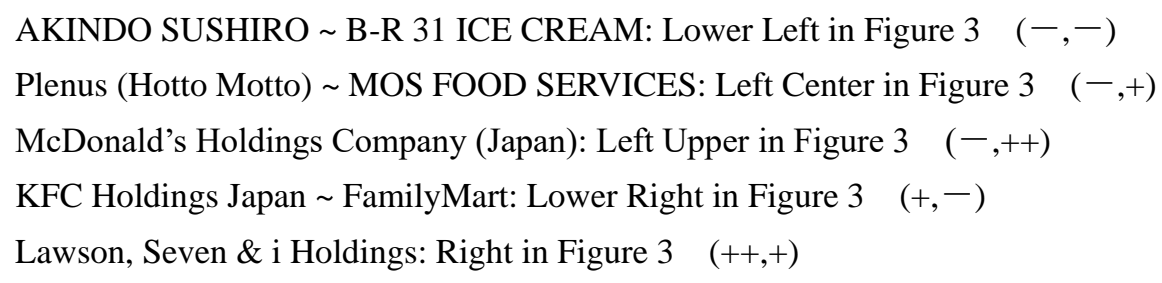

Lower two groups consist of positive part of 1st principal component and the upper groups consist of negative part of 1st principal component.

Each group of positive and negative part of 2 nd principal component is built by dividing the above big group. These are expressed in Figure 6.


Figure 6. Divided groups by Principal Component Analysis and Cluster Analysis

Principal Component Analysis has much more information than Cluster Analysis because Principal Component Analysis has the information of distance in the plotting plane. Principal Component Analysis and Cluster Analysis are not used at the same time so far, because the method and the objective of using it is quite different. But we have obtained marvelous results as stated above. This relationship should be examined in various cases. 


\section{Remarks}

\subsection{Convenience Store Industry}

We have obtained the result that Seven \& i Holdings and Lawson are in the high corporate performance, high frequency SNS utilization group. They have twitter followers for more than 2 million consumers and are distinct from other companies.

MINISTOP has rather small 380 thousand followers but the number of likes is 2811 which is the most in the convenience store industry. Total retweet is 966527 which is also the most in the convenience store industry. MINISTOP maybe makes some device for the consumers to retweet. Looking into the retweet in detail, MINISTOP makes tweet that if the consumers make follow and retweet, consumers can get coupon by lottery. Thus, many consumers make retweet.

\subsection{Restaurant Industry}

From Figure 3, we can observe that McDonald is overwhelming in retweet theme. The example of McDonald's campaign to stimulate retweet is as follows.

If consumers follow McDonald's account (@McDonalds Japan) and retweet the tweet which is to be executed on 20 o'clock May 23, 5 persons are selected by lottery and "Suitable burger" are given for the number of followers.

From Figure 4, we can observe that KFC Holdings Japan is in a high communication group. Followers are 540 thousand, which is $1 / 4$ compared with McDonald, but the number of tweet is 240 thousand, which is 30 times, and the number of follow is 6 thousand, which is 15 times, and the number of replies 3 thousand, which is 30 times compare with McDonald. KFC Holdings Japan is making device as follows.

Consumers can get KFC's LINE stamp by free of charge only by making follow even if the consumers do not retweet.

Thus each company is making every effort to sharpen swords.

\section{Conclusion}

Social Networking Service (SNS) is prevailing rapidly in Japan in recent years. Facebook, mixi and Twitter are the popular one. These are utilized in various field of life together with the convenient tool such as smart-phone. In this paper, principal component analysis and cluster analysis are executed in order to clarify the relationship among the corporate performance and the SNS utilization condition. We focus on restaurant industry and convenience store industry, where marketing competition which utilizes SNS to consumers is fierce. Marketing application would then be extracted.

The main results of principal component analysis are as follows.

In the chart of the 1st principal component ( $\mathrm{X}$ axis) and the 2nd principal component ( $\mathrm{Y}$ axis), we can observe the following 5 big clusters.

\section{Right: Seven \& i Holdings, Lawson}

This is a high corporate performance, high frequency SNS utilization group.

Left Upper: McDonald's Holdings Company (Japan)

This is a single group. It is strong for retweets group. It makes many campaign and has good communication with consumers.

\section{Lower Right: KFC Holdings Japan, SKYLARK (GUSTO), FamilyMart}

This cluster has the characteristics that corporate performance and scale are rather big and retweets group are slightly low.

Left: MOS FOOD SERVICES, KURACorporation, Plenus (Hotto Motto), MINISTOP

MOS FOOD SERVICES carries out the campaign, where the rival is McDonald. But it does not make so much hit as McDonald in the number of retweets.

Lower Left: ANRAKUTEI, Torikizoku, KAPPA CREATE, RINGER HUT, B-R 31 ICE CREAM, KOURAKUEN HOLDINGS, Torikizoku

Scale is rather small and the number of tweets is rather few. They do not make so much effort to SNS or it does not make so much hit. 
Cluster analysis was executed in order to confirm the relationship/closeness among companies. The data used were the same with those of principal component analysis.

In the principal component analysis for the 1st principal component and the 2nd principal component, we could observe 5 big clusters as stated above. Cluster analysis wholly coincided with these results. This is really an astonishing result. Principal Component Analysis and Cluster Analysis are not used at the same time so far, because the method and the objective of using it is quite different. But we have obtained marvelous results as stated above. This relationship should be examined in various cases.

These are utilized for constructing a much more effective and useful marketing plan building for SNS. Although it has a limitation that it is restricted in the number of research, we could obtain the fruitful results. To confirm the findings by utilizing the new consecutive records would be the future works to be investigated.

\section{References}

Kadowaki, T., Yamakata, Y., \& Tanaka, K. (2014). "Recipe search for blog-type recipe articles based on a user's situation" IEICE technical report 114, pp13-18.

Sako, R., \& Hara, M. (2013). "Implementation of Gender Recognition System for Twitter User" The 29th Fuzzy System Symposium (Osaka, September 9-11).

Tamai, M., et al. (2016). On Estimating Tendency toward Depression with Analysis of Tweet contents. The Association for Natural Language Processing, pp385-388. 
Appendix

\begin{tabular}{|c|c|c|c|c|c|c|c|c|c|c|}
\hline Name of enterprise & \multicolumn{2}{|c|}{ Financial } & Number of employees & \multirow{2}{*}{\multicolumn{2}{|c|}{$\begin{array}{r}\text { Amount of sales } \\
583,452,000,000\end{array}$}} & \multicolumn{2}{|c|}{ Per-store sales figures } & \multicolumn{2}{|c|}{ Operating Income } & Ordinary income \\
\hline Lawson & consolidated & & 5446 & & & & $44,500,953$ & \multicolumn{2}{|c|}{$72,541,000,000$} & $69,622,000,000$ \\
\hline Seven \& i Holdings & individual & & 440 & & $7,860,000,000$ & & $11,217,176$ & \multicolumn{2}{|c|}{$194,297,000,000$} & $193,329,000,000$ \\
\hline Family Mart & individual & & 5638 & & $5,203,000,000$ & & $7,151,143$ & \multicolumn{2}{|c|}{$23,183,000,000$} & $26,791,000,000$ \\
\hline KFC Holdings Japan & consolidated & & 4602 & & $3,032,000,000$ & & $76,616,188$ & \multicolumn{2}{|c|}{$2,558,000,000$} & $2,425,000,000$ \\
\hline ANRAKUTEI & consolidated & & $99,999,999$ & & 15272000000 & & $99,999,999$ & \multicolumn{2}{|c|}{$22,000,000$} & $243,000,000$ \\
\hline YOSHINOYA CO.,LTD & individual & & 173 & & $, 565,000,000$ & & $46,864,126$ & \multicolumn{2}{|c|}{$281,000,000$} & $344,000,000$ \\
\hline Duskin Co., Ltd.(Mister Donut) & individual & & 3667 & 134 & $+245,000,000$ & & $115,728,448$ & \multicolumn{2}{|c|}{$4,069,000,000$} & $6,478,000,000$ \\
\hline Plenus (Hotto Motto) & individual & & 9361 & 138 & $3,282,000,000$ & & $51,966,178$ & \multicolumn{2}{|c|}{$6,938,000,000$} & $7,590,000,000$ \\
\hline B-R 31 ICE CREAM & individual & & 333 & & $, 706,000,000$ & & $16,714,165$ & \multicolumn{2}{|c|}{$486,000,000$} & $557,000,000$ \\
\hline MINISTOP & consolidated & & 896 & & $9,955,000,000$ & & $87,032,700$ & \multicolumn{2}{|c|}{$1,241,000,000$} & $2,284,000,000$ \\
\hline McDonald's Holdings Company (Japan) & consolidated & & $99,999,999$ & & $, 646,000,000$ & & $77,858,468$ & \multicolumn{2}{|c|}{$6,930,000,000$} & $6,614,000,000$ \\
\hline SKYLARK (GUSTO) & consolidated & & $99,999,999$ & & $7,513,000,000$ & & $115,551,825$ & \multicolumn{2}{|c|}{$31,249,000,000$} & $28,952,000,000$ \\
\hline KURACorporation & consolidated & & 10270 & & 0949000000 & & $288,179,221$ & 651900 & 00000 & 6802000000 \\
\hline KAPPA CREATE & consolidated & & 112 & & 66257000000 & & $188,766,382$ & -66800 & 00000 & -522000000 \\
\hline MOS FOOD SERVICES & consolidated & & 1035 & & $, 346,000,000$ & & $38,433,186$ & $3,823,00$ & 00,000 & $4,090,000,000$ \\
\hline Torikizoku & consolidated & & $99,999,999$ & & 29336000000 & & $59,626,016$ & $1,457,00$ & 00,000 & $1,426,000,000$ \\
\hline CHIKARANOMOTO GLOBAL HOLDINGS & (IPI consolidated & & $99,999,999$ & & $, 983,000,000$ & & $14,909,774$ & 289,00 & 00,000 & $281,000,000$ \\
\hline RINGER HUT & consolidated & & 659 & & $, 104,000,000$ & & $31,217,391$ & $1,648,00$ & 00,000 & $2,520,000,000$ \\
\hline KOURAKUEN HOLDINGS & consolidated & & 4649 & & $7,423,000,000$ & & $26,512,868$ & $1,004,00$ & 00,000 & $1,362,000,000$ \\
\hline HOTLAND（Tsukiji Gindako） & consolidated & & $99,999,999$ & & $, 536,000,000$ & & $39,903,759$ & $1,492,00$ & 00,000 & $1,416,000,000$ \\
\hline AKINDO SUSHIRO & individual & & $99,999,999$ & & 6402000000 & & $353,850,679$ & 920400 & 00000 & 8995000000 \\
\hline Pepper Food Service Co., Ltd. & individual & & 365 & & 22337000000 & & $82,121,324$ & 99,99 & 99,999 & 1033000000 \\
\hline COCO'S JAPAN CO. & individual & & 6219 & & $3,532,000,000$ & & $100,226,027$ & 99,99 & 99,999 & $2,481,000,000$ \\
\hline TORIDOLL (MARUKAME UDON) & individual & & 9379 & & $, 611,000,000$ & & $102,179,019$ & $9,886,00$ & 00,000 & $9,498,000,000$ \\
\hline Ohsho Food Service Corporation & individual & & 8138 & & $5,078,000,000$ & & $104,711,297$ & $5,494,00$ & 00,000 & $5,801,000,000$ \\
\hline The ordinary profit rate (sales) & Net Income & Net income per share & Total ass & & Net assets & per share & Sales volume & e per person & Net it & income per person \\
\hline $11.93 \%$ & $31,381,000,000$ & 313.81 & $803,212,00$ & 0,000 & & $2,643.97$ & & $107,134,043.33$ & & $5,762,210.80$ \\
\hline $88.74 \%$ & $73,558,000,000$ & 83.18 & $1,845,861,00$ & 0,000 & & $1,670.18$ & & $495,136,363.64$ & & $167,177,272.73$ \\
\hline $15.29 \%$ & $10,519,000,000$ & 95.03 & $918,059,00$ & 0,000 & & $3,929.84$ & & $31,075,381.34$ & & $1,865,732.53$ \\
\hline $2.75 \%$ & $1,365,000,000$ & 60.9 & $39,484,00$ & 0,000 & & 944.43 & & $19,129,074.32$ & & $296,610.17$ \\
\hline $1.59 \%$ & $25,000,000$ & 11.92 & $13,556,00$ & 0,000 & & 2594.16 & & $99,999,999$ & & $99,999,999$ \\
\hline $0.61 \%$ & $1,500,000,000$ & 23.25 & $84,713,00$ & 0,000 & & 791.05 & & $326,965,317.92$ & & $8,670,520.23$ \\
\hline $4.83 \%$ & $3,723,000,000$ & 68.09 & 99,99 & 9,999 & & $99,999,999$ & & $36,608,944.64$ & & $1,015,271.34$ \\
\hline $5.49 \%$ & $4,221,000,000$ & 110.27 & $91,351,00$ & 0,000 & & $1,711.27$ & & $14,772,139.73$ & & $450,913.36$ \\
\hline $2.83 \%$ & $175,000,000$ & 18.2 & $18,364,00$ & 0,000 & & 995.02 & & $59,177,177.18$ & & $525,525.53$ \\
\hline $1.16 \%$ & $215,000,000$ & 7.43 & $121,395,00$ & 0,000 & & $1,970.28$ & & $219,815,848.21$ & & $239,955.36$ \\
\hline $2.92 \%$ & $5,366,000,000$ & 40.37 & $180,499,00$ & 0,000 & & 827.32 & & $99,999,999$ & & $99,999,999$ \\
\hline $8.17 \%$ & $18,213,000,000$ & 93.57 & $318,317,00$ & 0,000 & & 586.13 & & $99,999,999$ & & $99,999,999$ \\
\hline $6.13 \%$ & 4389000000 & 222.31 & 461120 & 00000 & & 1533.41 & & $10,803,213.24$ & & $427,361.25$ \\
\hline$-0.79 \%$ & -6304000000 & -129.63 & $27,687,00$ & 0,000 & & 228.22 & & $591,580,357.14$ & & $-56,285,714.29$ \\
\hline $7.81 \%$ & $2,358,000,000$ & 75.72 & $55,063,00$ & 0,000 & & $1,359.84$ & & $50,575,845.41$ & & $2,278,260.87$ \\
\hline & 967000000 & 83.55 & 159420 & 00000 & & 546.58 & & 293.36 & & 9.67 \\
\hline $14.17 \%$ & $242,000,000$ & 23.48 & $6,690,00$ & 0,000 & & 317.55 & & $99,999,999$ & & $99,999,999$ \\
\hline $12.53 \%$ & $1,592,000,000$ & 71.98 & $30,721,00$ & 0,000 & & 678.8 & & $30,506,828.53$ & & $2,415,781.49$ \\
\hline $9.44 \%$ & $963,000,000$ & 61.8 & $21,393,00$ & 0,000 & & 533.58 & & $3,102,387.61$ & & $207,141.32$ \\
\hline $5.34 \%$ & $-751,000,000$ & -40.97 & $14,816,00$ & 0,000 & & 213.28 & & $99,999,999$ & & $99,999,999$ \\
\hline $5.75 \%$ & 6952000000 & 253.16 & 12556200 & 0000 & & 1145.36 & & $99,999,999$ & & $99,999,999$ \\
\hline $4.62 \%$ & 633000000 & 64.7 & 99,99 & 9,999 & & $99,999,999$ & & $99,999,999$ & & $99,999,999$ \\
\hline $4.24 \%$ & $1,450,000,000$ & 85.46 & 99,99 & 9,999 & & $99,999,999$ & & $9,411,802.54$ & & $233,156.46$ \\
\hline $10.60 \%$ & $5,467,000,000$ & 126.48 & $53,601,00$ & 0,000 & & 652.34 & & $9,554,430.11$ & & $582,897.96$ \\
\hline $7.73 \%$ & $3,839,000,000$ & 203.92 & $64,727,00$ & 0,000 & & $2,341.11$ & & $9,225,608.26$ & & $471,737.53$ \\
\hline
\end{tabular}




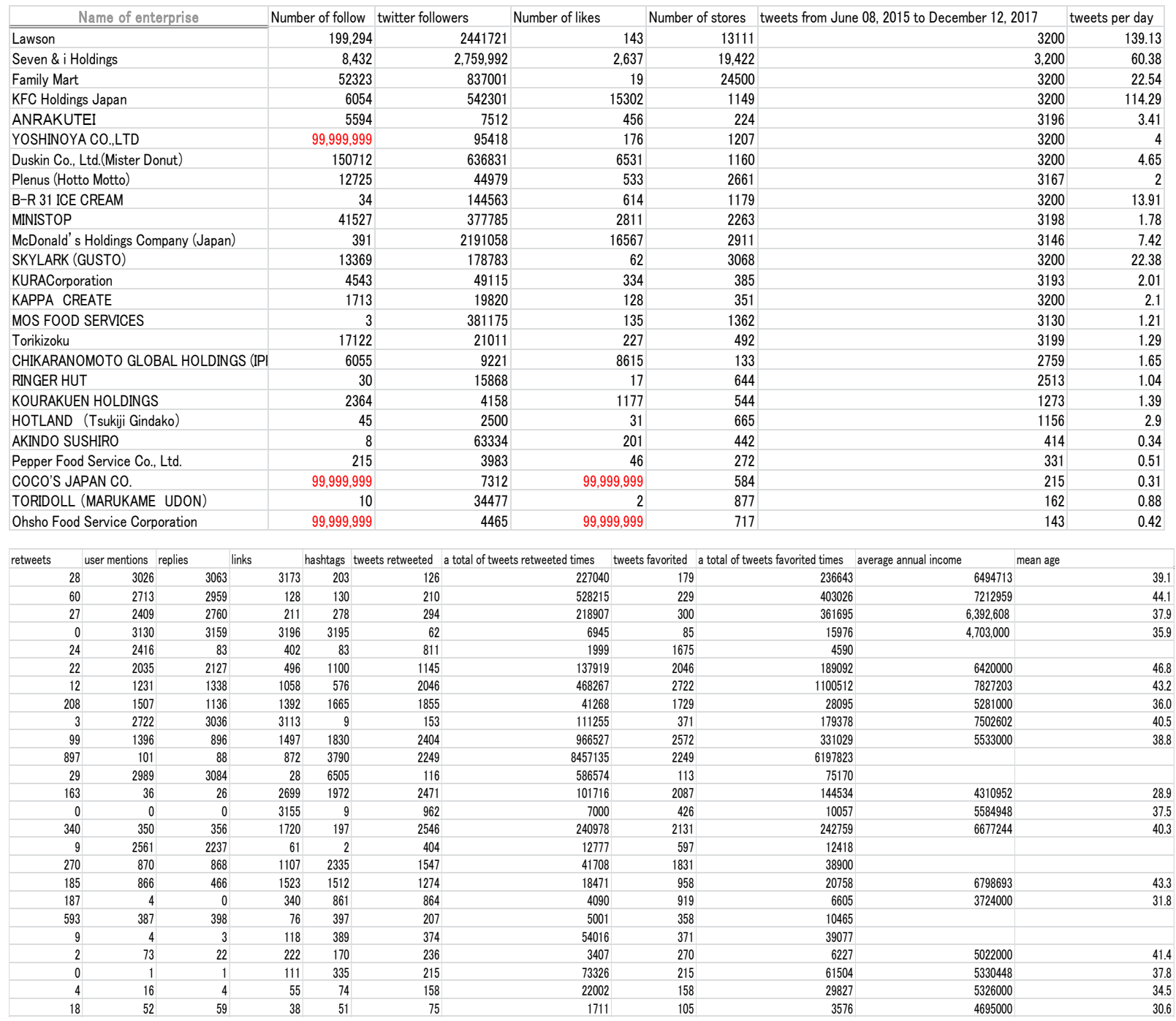

※Missing data is set to $99,999,999$

\section{Copyrights}

Copyright for this article is retained by the author(s), with first publication rights granted to the journal.

This is an open-access article distributed under the terms and conditions of the Creative Commons Attribution license (http://creativecommons.org/licenses/by/4.0/). 